\title{
MicroRNAs orchestrating senescence of endothelial and vascular smooth muscle cells
}

\author{
Ornella Colpani and Gaia Spinetti \\ IRCCS MultiMedica, Milan, Italy
}

Correspondence should be addressed to G Spinetti: gaia.spinetti@multimedica.it

\begin{abstract}
During organism aging, the process of cellular senescence is triggered by critical stressors such as DNA damage, oncogenes, oxidative stress, and telomere erosion, and vascular cells are not exempted. Senescent cells stop proliferating but remain metabolically active producing pro-inflammatory signals in the environment collectively named senescenceassociated secretory phenotype (SASP) that contribute to the amplification of the response to the neighbor and distant cells. Although the shift toward senescence is protective against tumors and needed during wound healing, the accumulation of senescent cells during aging due to an impairment of the immune system deputed to their clearance, can predispose to diseases of the cardiovascular system such as atherosclerosis. In this short review, we describe the main features of senescence of endothelial and smooth muscle cells and focus on the role non-coding RNAs of the microRNAs class in controlling this process. Finally, we discuss the potential of new strategies based on senescence removal in counteracting vascular disease burden.
\end{abstract}

\section{Causes and features of becoming a senescent cell}

Cells become senescent at different stages of the life of mammals and their presence in a given organ is needed for the correct development, proper wound healing, and tumor suppression (1). Excessive extracellular or intracellular stress triggers cellular senescence (CS) in proliferation-competent cells inducing growth arrest and failure to re-enter the cell division cycle. In addition to durable growth arrest, senescent cells show high SA $\beta$-gal activity, activate damage sensing pathways, and express anti-proliferative molecules. Since senescent cells are still metabolically active they become a source of secreted molecules including IL-1, IL-6, IL-8, VEGFA, and matrix metalloproteinases (MMPs) collectively named senescentassociated secretory phenotype (SASP). SASP-associated propagation of senescence to other cells and organs, the so-called 'bystander effect', amplifies the detrimental effect in aging and diseases of the low abundant population of senescent cells (about 15\% of the total cells of an old primate). In addition other still not completely known mechanisms may also contribute to the bystander effect as suggested by a recent study where no SASP was observed in transplanted senescent cells (2).

Among the stresses responsible for CS, telomere shortening is one of the well investigated. Indeed, a critical telomere shortening or the loss of telomere capping leads to chromosome fusion and genome instability with consequent CS. Similarly, senescence is a cellular response to severe DNA damage, in spite of the genomic location. For example, a cause of CS is the strong or chronic exposure to mitogenic signals which provokes 
DNA damage by replicon fork collapse (3). Of note, mitochondrial dysfunction associated to aging induces a specific form of senescence response (mitochondrial dysfunction-associated senescence (MiDAS)) characterized by a secretory phenotype which is different from that caused by genotoxic stress and lacks of IL-1-dependent inflammatory signal (4).

Molecular pathways downstream the CS triggers generally act through p53/p21 and p16 INK4a/pRB pathways, which are often sufficient to arrest cellular growth (3). On the other hand, SASP is under the control of other pathways such as NF-kB and ATM. NOTCH1 was shown to be crucial for the regulation of SASP composition and temporal action and for lateral induction of senescence (5). In particular, oncogeneinduced senescence is accompanied by an increase in NOTCH1 activity which drives TGF- $\beta$-enriched secretome, while NOTCH1 inhibition during senescence facilitates the upregulation of pro-inflammatory cytokines. Thus, the dynamic modulation of NOTCH signaling regulates the balance between TGF- $\beta$ enriched secretome and the canonical SASP.

As mentioned, induction of senescence can be beneficial since it arrests the growth of cells with damaged DNA or altered chromatin remodeling exerting tumor suppression. However, SASP can modify the microenvironment and senescent cells can induce a DNA damage response in neighboring cells via gap junction and processes involving reactive oxygen species generation (6). Therefore, senescence-associated changes in tissues may predispose to the development of diseases including those of the vascular system that dramatically increase during aging.

\section{Senescence of endothelial and vascular smooth muscle cells}

Several observations indicate that aging and senescence are processes which contribute to the onset of cardiovascular diseases, and may also exacerbate pathological conditions. For instance, with aging the pro-inflammatory environment of the arterial wall associates with profound cellular and matrix modifications, which create a suitable condition for the development of hypertension and atherosclerosis (7). Both endothelial cells (ECs) and vascular smooth muscle cells (VSMCs) are affected by acquiring a senescent phenotype with distinct characteristics as briefly described below (Fig. 1).

\section{Endothelial cells (ECs)}

ECs form the outer layer of large vessel walls and therefore are first in line to sense systemic insults. The functional role of senescent EC in vascular homeostasis is still not completely understood as their presence may be both protective and damaging as they accumulate. In line with this, senescent ECs have been identified in atheroprone sites, and their presence seems to be the consequence of different factors including flow perturbation (8). Senescent ECs may participate in the pathogenesis of cardiovascular diseases since they exhibit a diminished angiogenic potential and impaired eNOS activity with increased plasminogen activator inhibitor 1 expression, thus acquiring a pro-thrombotic phenotype (9). However, evidence suggests that senescent ECs could also acquire an anti-inflammatory phenotype. In 2010 Coleman et al.
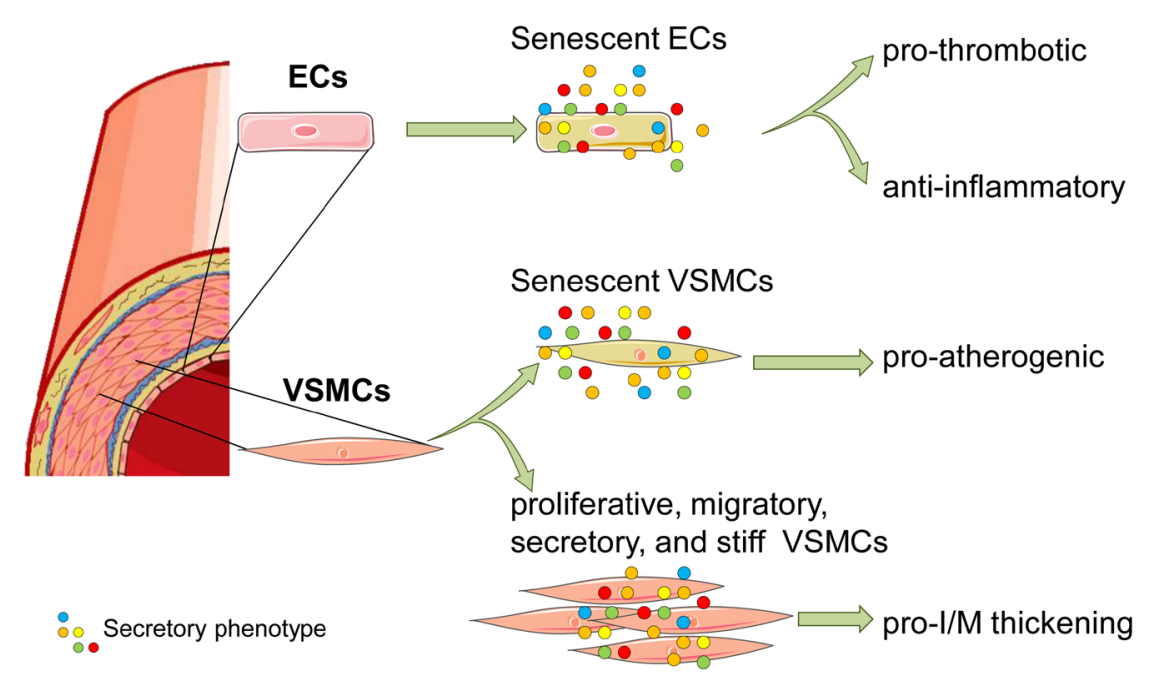

Figure 1

Aging-associated phenotypes of endothelial cells (ECs) and vascular smooth muscle cells (VSMCs). With aging, ECs undergo cellular senescence acquiring a dual function i.e. pro-thrombotic and anti-inflammatory. Differently from ECs, VSMCs exhibit two age-associated different phenotypes: a subset become senescent, whereas another one become proliferative, migratory, secretory and stiff both contributing to intima/media (I/M) thickening of arteries.

https://vb.bioscientifica.com https://doi.org/10.1530/VB-19-0017 (c) 2019 The authors Published by Bioscientifica Ltd

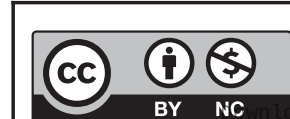

This work is licensed under a Creative Commons Attribution-NonCommercial 4.0 International License. 
showed that stress-induced premature senescence (SISP), mediated by SENEX gene, leads to reduced synthesis of IL-8. Notably, IL-8 is responsible for neutrophil transendothelial cell migration and is also a downstream effector of C-reactive protein (10).

\section{Vascular smooth muscle cells (VSMCs)}

With aging, VSMCs shift to different phenotypes: a subset of VSMCs becomes senescent, while another one becomes more proliferative, migratory, secretory and stiff (11). All these events are ascribable to increases in molecules of sympathetic nerve activity, reninangiotensin-aldosterone system and endothelin-1, which sustain a proinflammatory process in the vessel wall $(11,12)$. VSMC senescence has been associated with the worsening of pathological conditions. For instance, advanced atherosclerotic plaques contain VSMCs which exhibit the classical SASP. The secretion of MMPs and inflammatory cytokines leads to plaque instability, with the risk of rupture and thrombosis $(7,13)$. Nevertheless, besides SASP, senescent cells can sustain atherosclerosis with other mechanisms still not completely known. For instance, transgenic mice bearing the loss-of-function mutation of telomeric repeat-binding factor-2 (TRF2) show the formation of a necrotic core within the plaques in the absence of SASP. Interestingly, reduced expression of TRF2 has been associated with senescent VSMCs in human atherosclerotic lesions (14).

\section{MicroRNAs are master regulators of vascular cell senescence}

miRNAs are a class of small non-coding RNAs which repress gene expression mostly by inhibiting the translation or promoting the degradation of their mRNA targets. Being central in controlling cell function in virtually all physiological and pathological contexts, an imbalance in miRNA expression/function affects also vascular cell senescence and contributes to atherosclerosis (Fig. 2) (15). Examples of senescence miRNAs is the miR-17-92 cluster which is downregulated in ECs with aging, target factors involved in cell growth arrest and matrix production, such as p21/CDKN1A (16) and thrombospondin1 (17). Recently, Espinosa-Diez et al. have demonstrated a miRNA-mediated connection between DNA damage (one of the most common causes of cellular senescence) and angiogenesis. Authors found that miR-494 levels increase in response to DNA damage and lead to endothelial senescence and reduction in angiogenic sprouting (18). Other miRNAs inducing a senescent state of EC include miR-217 (19) and miR-34a (20), which target the deacetylase sirtuin-1 (SIRT1), a pivotal player in cell survival and senescence.

The most studied 'SASP-miRNAs' are miR-146a/b that negatively regulate IL-6 and IL-8 secretion. In ECs $\mathrm{miR}-146 \mathrm{a} / \mathrm{b}$ are overexpressed in the late stage of the inflammatory response and act by suppressing pro-inflammatory transcription factors. In particular, miR-146a/b negatively modulate NF-kB and EGR

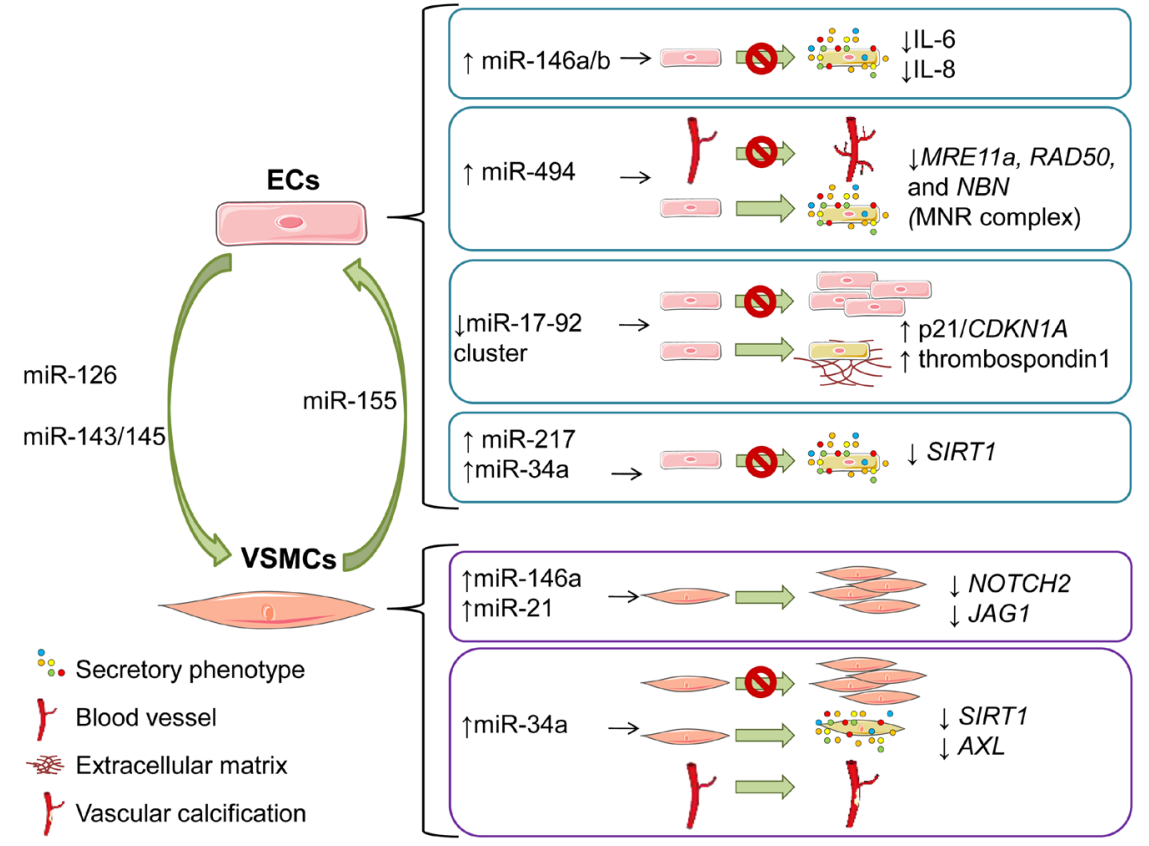

\section{Figure 2}

MicroRNA control of vascular cell senescence. Schematic view of miRNAs regulating pathway associated with senescence of vascular cells of the arterial wall. Changes in the expressional levels, the target genes that are modulated, miRNAs that are transferred between cell types, and the functional consequences are depicted for ECs and VSMCs. https://vb.bioscientifica.com https://doi.org/10.1530/VB-19-0017
(C) 2019 The authors Published by Bioscientifica Ltd
This work is licensed under a Creative Commons Attribution-NonCommercial 4.0 International License.

ded from Bioscientifica.com at 04/26/2023 06:43:25AM 
pathways, which are known to be implicated in senescence and atherogenesis. Thus, it is conceivable that $\mathrm{miR}-146 \mathrm{a} / \mathrm{b}$ may have a protective role during the early atherogenic process (21). Coherently with this possible implication, the presence of upregulation of miR-146a/b has been documented also in aortic and femoral atherosclerotic plaques (22). Other age-associated miRNAs were found to be upregulated in atherosclerotic plaques, that is, miR-21 and miR-34a (22). These results were partially confirmed by Cao et al. who showed that miR-146a and miR-21 were upregulated in atherosclerotic lesions and cooperated to modulate the proliferation of VSMCs. In particular, the upregulation of miR146a and miR-21 resulted in the inhibition of NOTCH2 and JAG1, promoting the formation of atherosclerotic plaques. However, no differences in miR-34a, and miR-146b, expression were observed between atherosclerotic plaque and normal controls (23). On the other hand, Badi et al. showed that miR-34a is upregulated in aged murine aortas, where it promoted the senescent process and vascular calcification of VSMCs (24), a well-known complication of atherosclerosis. A recent study pointed out that miR-21 which induces VSMCs proliferation during atherogenesis is also controlling inflammation during atherogenesis. Indeed, the deficiency of miR-21 in hematopoietic cells augmented necrosis within the atherosclerotic lesions of

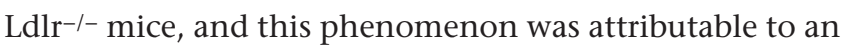
increase in macrophage apoptosis (25).

Due to their potential to be transferred between cells via different mechanisms including vesicle-mediated ones, miRNAs are also involved in the EC-VSMC crosstalk, both in physiological and pathological conditions. miR155 is an intriguing miRNA involved in aging-associated pathologies. Its levels were found downregulated in murine VSMCs with aging, and this contributed to vasoconstriction (26). Nevertheless, KLF5-overexpressing VSMCs secrete miR-155-rich exosomes (small size actively released vesicles), which negatively affect EC functions (27). In the context of atherosclerosis, EC-derived apoptotic bodies containing miR-126 limit atheroprogression by promoting the mobilization and incorporation of SCA1+ progenitor cells during plaque formation (28). However, miR-126 acts as a paracrine mediator on VSMCs, increasing their turnover and promoting an atherogenic phenotype. Interestingly, increased levels of miR-126 were found in the athero-susceptible areas characterized by disturbed flow (29). Other atheroprotective miRNAs are miR-143/145, which are upregulated in EC under laminar shear stress and which target gene expression in VSMCs (30).
What emerges from these studies is that miRNAs constitute a complex network, contributing to the development of the vascular diseases. Furthermore, it is worth considering that the same miRNA may exert opposite roles during the pathogenesis of vascular disease, as for miR-146a which is protective during the early atherogenic process but also promotes the proliferation of VSMCs. More research is needed to clarify the relative contributions of each player and the future potential therapeutically valuable options.

\section{Protecting the vessels by targeting vascular senescence}

Due to the strong causative role of senescence in ageassociated dysfunctions, it has been proposed that the elimination of senescent cells could be beneficial. In the last 5 years, several lines of evidence confirmed this hypothesis, revolutionizing the field of aging and supporting the idea that it could be a condition therapeutically targetable, thus including the deadly ageassociated vascular diseases.

In young age, senescent cell accumulation is taken under control by the immune system through different mechanisms mostly mediated by the recruitment of $\mathrm{T}$ cells via SASP factors (31). This process is progressively damaged during the lifetime. Studies demonstrate that immune decline associates with morbidity and mortality with aging, vice versa healthy aging rely on a strong immune system (32). A very recent article directly demonstrated that immune surveillance of senescence via perforin-induced cell apoptosis is needed to counteract the development of age-associated diseases and the negative impact on longevity (33). A drug that selectively eliminates senescent cells, a senolytic, ABT-737, was able to revert the aging phenotype observed in perforin-deficient mice. While the concept of senolytic, senescence-targeting drug, is relatively new, its exploitation is becoming increasingly popular in aging and may be transferable to vascular diseases. The first genetic proof that removing cells bearing the senescent phenotype delay aging came from the group of Kirkland and van Deursen who generate a genetically modified mouse that carries the INK-ATTAC transgene for the inducible elimination of the cells with p16 ${ }^{\text {Ink4a }}$ senescence biomarker (34). Kirkland group further theorized that since senescent cells are viable and exhibit a special ability to resist to stress-induced damage and to the negative action of the cytokine/growth factor they are secreting, the way to remove them is by specifically

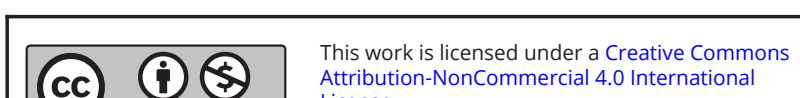
Attribution-NonCommercial 4.0 International License. ded from Bioscientifica.com at 04/26/2023 06:43:25AM 
interfere with the anti-apoptotic and pro-survival pathway they rely on (35). The first compounds with this activity discovered are dasatinib (D) and quercetin (Q) that target with different mechanisms preadipocytes and ECs, respectively. The cocktail of $\mathrm{D}+\mathrm{Q}$ has been proven effective as an intermittent therapy with a non-specific effect on age-associated disease, thus potentially powerful for increasing lifespan and health span and to combat geriatric frailty (36). Evidence in support of the application of this approach to cardiovascular diseases includes the study of $\mathrm{LdLr}^{-/-}$mice atherosclerotic plaque that results dependent on senescent cell-mediated instability via MMPs and increased inflammation. Senolytic therapy may be a protective strategy in this context as indicated by a recent study employing both $\mathrm{p} 16^{\text {Ink4a }}$ transgenic mice and ABT263, that target the anti-apoptotic proteins BCL2 and Bcl-xL (BCL2L1) and selectively destroy senescent cells (37, 38). However, $D+Q$ treatment did not prove effective in reducing plaque size in a previous study on aged or lipidfed mice although it alleviates vasomotor dysfunction, pointing at a still not completely unraveled way of action and specificity of different senolytic compounds (39). Senolytics have now reached the clinical arena with the results of the first-in-human trial on a small group of 14 patients with idiopathic pulmonary fibrosis released this year (40). Of note, a gain in the 6-min walking distance test (6MWD) after $\mathrm{D}+\mathrm{Q}$ treatment was associated with lowered blood circulating miR-34c pointing at a potential association between senescence clearance and miRNAs (40) (Fig. 3).
In addition to senescent cell removal, scientists are striving to find an approach to reverse senescence itself, since this could be crucial for prolonged healthy life span. Cell reprogramming could be a promising strategy since the generation of induced pluripotent stem cells (iPSCs) allows to reset epigenetic state of cells. However, this kind of approach has several limitations in vivo, such as the teratogenic potential of iPSCs. For senescence reversion one may think to exploit the capacity of miRNAs to tune the process. In addition to those miRNAs described in the other sections of this article, miR-302-367 has been identified as a miRNA whose ectopic expression can induce cell reprogramming by targeting epigenetic factors and p53-p21 pathways and by inducing the expression of OCT4, NANOG and SOX2 representing future players to rescue cells from senescence (41). The expressional level of a given miRNA could be tuned to the physiological one by inhibition via miRNA locked nucleic acid (LNA)-modified anti-miRNA in addition to decoys or sponges. MiRNA could also be transferred to target cells via engineered vesicles mimicking the endogenous mechanisms. These approaches are under clinical investigations in different pathological conditions demonstrating feasibility (42).

\section{Conclusions}

With aging the increasing number of cells in a senescent state, even if they represent a very low abundant cell population, is associated with dramatic changes in organ

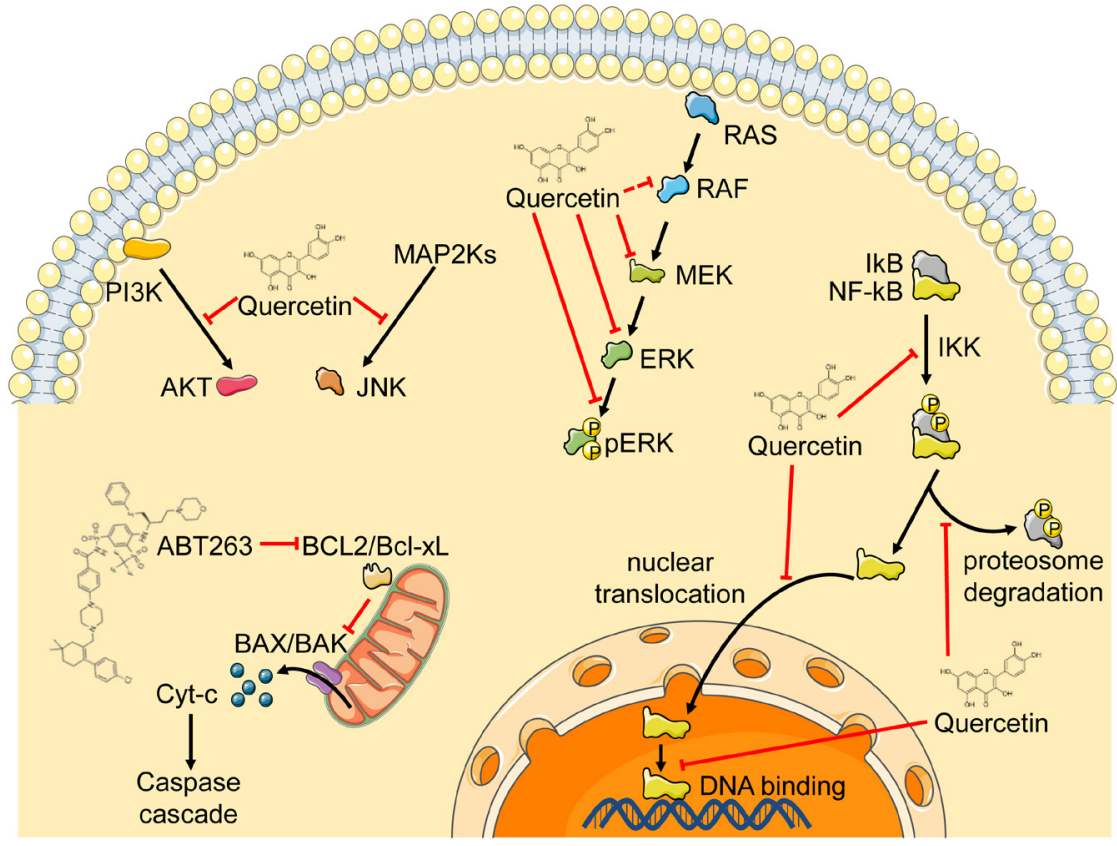

https://vb.bioscientifica.com https://doi.org/10.1530/VB-19-0017 (c) 2019 The authors Published by Bioscientifica Ltd

\section{Figure 3}

Mechanisms of action of ABT263 and Quercetin. Schematic view of the molecular pathways targeted by the compounds. While ABT263 binds and blocks BCL2/BCl-xL, quercetin acts by blocking diverse steps of JNK, PI3K, RAS/RAF/MEK/ERK and NF-kB pathways. 
functionality. This is the case also for the arterial wall where senescent ECs and VSMCs may predispose and aggravate vascular disease as atherosclerosis. Mechanisms that lead a cell to become senescent are mostly associated with the activation of pathways of survival and anti-apoptosis. The release of SASP molecules amplifies the senescent effect. Non-coding miRNAs are emerging player in the tuning of this shift being both implicated in autologous and paracrine senescence. Although huge attention is devoted to the study of senolytics, compounds that have the capacity to eliminate active senescent cells recognized based on the pro-survival pathways, other strategies similar to anti-cancer new therapies deserve attention and are represented by immune system boosting or engineering to empower the natural senescence surveillance that is impaired with aging and in vascular diseases. Whether manipulating miRNAs expression modulation may be exploited to tune these processes is still an open question.

\section{Declaration of interest}

The authors declare that there is no conflict of interest that could be perceived as prejudicing the impartiality of this review.

\section{Funding}

This work has been supported by the Italian Ministry of Health Ricerca Corrente to the IRCCS MultiMedica and by the Cariplo Foundation (Rif 2016-0922).

\section{References}

1 He S \& Sharpless NE. Senescence in health and disease. Cell 2017169 1000-1011. (https://doi.org/10.1016/j.cell.2017.05.015)

2 da Silva PFL, Ogrodnik M, Kucheryavenko O, Glibert J, Miwa S, Cameron K, Ishaq A, Saretzki G, Nagaraja-Grellscheid S, Nelson G, et al. The bystander effect contributes to the accumulation of senescent cells in vivo. Aging Cell 201918 e12848. (https://doi. org/10.1111/acel.12848)

3 Campisi J. Aging, cellular senescence, and cancer. Annual Review of Physiology 201375 685-705. (https://doi.org/10.1146/annurevphysiol-030212-183653)

4 Wiley CD, Velarde MC, Lecot P, Liu S, Sarnoski EA, Freund A, Shirakawa K, Lim HW, Davis SS, Ramanathan A, et al. Mitochondrial dysfunction induces senescence with a distinct secretory phenotype. Cell Metabolism 201623 303-314. (https://doi.org/10.1016/j. cmet.2015.11.011)

5 Hoare M, Ito Y, Kang TW, Weekes MP, Matheson NJ, Patten DA, Shetty S, Parry AJ, Menon S, Salama R, et al. NOTCH1 mediates a switch between two distinct secretomes during senescence. Nature Cell Biology 201618 979-992. (https://doi.org/10.1038/ncb3397)

6 Nelson G, Wordsworth J, Wang C, Jurk D, Lawless C, Martin-Ruiz C \& von Zglinicki T. A senescent cell bystander effect: senescenceinduced senescence. Aging Cell 201211 345-349. (https://doi. org/10.1111/j.1474-9726.2012.00795.x)
7 Ungvari Z, Tarantini S, Donato AJ, Galvan V \& Csiszar A. Mechanisms of vascular aging. Circulation Research 2018123 849-867. (https://doi.org/10.1161/CIRCRESAHA.118.311378) 8 Warboys CM, de Luca A, Amini N, Luong L, Duckles H, Hsiao S, White A, Biswas S, Khamis R, Chong CK, et al. Disturbed flow promotes endothelial senescence via a p53-dependent pathway. Arteriosclerosis, Thrombosis, and Vascular Biology $201434985-995$. (https://doi.org/10.1161/ATVBAHA.114.303415)

9 Mistriotis P \& Andreadis ST. Vascular aging: molecular mechanisms and potential treatments for vascular rejuvenation. Ageing Research Reviews 201737 94-116. (https://doi.org/10.1016/j.arr.2017.05.006)

10 Coleman PR, Hahn CN, Grimshaw M, Lu Y, Li X, Brautigan PJ, Beck K, Stocker R, Vadas MA \& Gamble JR. Stress-induced premature senescence mediated by a novel gene, SENEX, results in an antiinflammatory phenotype in endothelial cells. Blood $2010 \mathbf{1 1 6}$ 4016-4024. (https://doi.org/10.1182/blood-2009-11-252700)

11 Wang M, Monticone RE \& McGraw KR. Proinflammatory arterial stiffness syndrome: a signature of large arterial aging. Journal of Vascular Research 201855 210-223. (https://doi. org/10.1159/000490244)

12 Li R, Mi X, Yang S, Yang Y, Zhang S, Hui R, Chen Y \& Zhang W. Long-term stimulation of angiotensin II induced endothelial senescence and dysfunction. Experimental Gerontology 2019119 212-220. (https://doi.org/10.1016/j.exger.2019.02.012)

13 Uryga AK \& Bennett MR. Ageing induced vascular smooth muscle cell senescence in atherosclerosis. Journal of Physiology $2016 \mathbf{5 9 4}$ 2115-2124. (https://doi.org/10.1113/JP270923)

14 Wang J, Uryga AK, Reinhold J, Figg N, Baker L, Finigan A, Gray K, Kumar S, Clarke M \& Bennett M. Vascular smooth muscle cell senescence promotes atherosclerosis and features of plaque vulnerability. Circulation 2015132 1909-1919. (https://doi. org/10.1161/CIRCULATIONAHA.115.016457)

15 Kataoka M \& Wang DZ. Non-coding RNAs including miRNAs and lncRNAs in cardiovascular biology and disease. Cells 20143 883-898. (https://doi.org/10.3390/cells3030883)

16 Hackl M, Brunner S, Fortschegger K, Schreiner C, Micutkova L, Mück C, Laschober GT, Lepperdinger G, Sampson N, Berger P, et al. miR-17, miR-19b, miR-20a, and miR-106a are down-regulated in human aging. Aging Cell 20109 291-296. (https://doi.org/10.1111/ j.1474-9726.2010.00549.x)

17 Florio MC, Magenta A, Beji S, Lakatta EG \& Capogrossi MC. Aging, microRNAs, and heart failure. Current Problems in Cardiology 2019 Epub. (https://doi.org/10.1016/j.cpcardiol.2018.12.003)

18 Espinosa-Diez C, Wilson R, Chatterjee N, Hudson C, Ruhl R, Hipfinger C, Helms E, Khan OF, Anderson DG \& Anand S. MicroRNA regulation of the MRN complex impacts DNA damage, cellular senescence, and angiogenic signaling. Cell Death and Disease 20189 632. (https://doi.org/10.1038/s41419-018-0690-y)

19 Menghini R, Casagrande V, Cardellini M, Martelli E, Terrinoni A, Amati F, Vasa-Nicotera M, Ippoliti A, Novelli G, Melino G, et al. MicroRNA 217 modulates endothelial cell senescence via silent information regulator 1. Circulation 2009120 1524-1532. (https:// doi.org/10.1161/CIRCULATIONAHA.109.864629)

20 Ito T, Yagi S \& Yamakuchi M. MicroRNA-34a regulation of endothelial senescence. Biochemical and Biophysical Research Communications 2010398 735-740. (https://doi.org/10.1016/j. bbrc.2010.07.012)

21 Cheng HS, Sivachandran N, Lau A, Boudreau E, Zhao JL, Baltimore D, Delgado-Olguin P, Cybulsky MI \& Fish JE. MicroRNA-146 represses endothelial activation by inhibiting pro-inflammatory pathways. EMBO Molecular Medicine 20135 1017-1034. (https://doi. org/10.1002/emmm.201202318)

22 Raitoharju E, Lyytikainen LP, Levula M, Oksala N, Mennander A, Tarkka M, Klopp N, Illig T, Kahonen M, Karhunen PJ, et al. miR21, miR-210, miR-34a, and miR-146a/b are up-regulated in human atherosclerotic plaques in the Tampere Vascular Study.

This work is licensed under a Creative Commons Attribution-NonCommercial 4.0 International License. 
Atherosclerosis 2011219 211-217. (https://doi.org/10.1016/j. atherosclerosis.2011.07.020)

23 Cao J, Zhang K, Zheng J \& Dong R. MicroRNA-146a and -21 cooperate to regulate vascular smooth muscle cell proliferation via modulation of the Notch signaling pathway. Molecular Medicine Reports 201511 2889-2895. (https://doi.org/10.3892/mmr.2014.3107)

24 Badi I, Mancinelli L, Polizzotto A, Ferri D, Zeni F, Burba I, Milano G, Brambilla F, Saccu C, Bianchi ME, et al. miR-34a promotes vascular smooth muscle cell calcification by downregulating SIRT1 (sirtuin 1) and axl (AXL receptor tyrosine kinase). Arteriosclerosis, Thrombosis, and Vascular Biology 201838 2079-2090. (https://doi.org/10.1161/ ATVBAHA.118.311298)

25 Canfran-Duque A, Rotllan N, Zhang X, Fernandez-Fuertes M, Ramirez-Hidalgo C, Araldi E, Daimiel L, Busto R, FernandezHernando C \& Suarez Y. Macrophage deficiency of miR-21 promotes apoptosis, plaque necrosis, and vascular inflammation during atherogenesis. EMBO Molecular Medicine 20179 1244-1262. (https:// doi.org/10.15252/emmm.201607492)

26 DuPont JJ, McCurley A, Davel AP, McCarthy J, Bender SB, Hong K, Yang Y, Yoo JK, Aronovitz M, Baur WE, et al. Vascular mineralocorticoid receptor regulates microRNA-155 to promote vasoconstriction and rising blood pressure with aging. JCI Insight 20161 e88942. (https://doi.org/10.1172/jci.insight.88942)

27 Zheng B, Yin WN, Suzuki T, Zhang XH, Zhang Y, Song LL, Jin LS, Zhan H, Zhang H, Li JS, et al. Exosome-mediated miR-155 transfer from smooth muscle cells to endothelial cells induces endothelial injury and promotes atherosclerosis. Molecular Therapy 201725 1279-1294. (https://doi.org/10.1016/j.ymthe.2017.03.031)

28 Zernecke A, Bidzhekov K, Noels H, Shagdarsuren E, Gan L, Denecke B, Hristov M, Koppel T, Jahantigh MN, Lutgens E, et al. Delivery of microRNA-126 by apoptotic bodies induces CXCL12dependent vascular protection. Science Signaling 20092 ra81. (https:// doi.org/10.1126/scisignal.2000610)

29 Zhou J, Li YS, Nguyen P, Wang KC, Weiss A, Kuo YC, Chiu JJ, Shyy JY $\&$ Chien S. Regulation of vascular smooth muscle cell turnover by endothelial cell-secreted microRNA-126: role of shear stress. Circulation Research 2013113 40-51. (https://doi.org/10.1161/ CIRCRESAHA.113.280883)

30 Hergenreider E, Heydt S, Treguer K, Boettger T, Horrevoets AJ, Zeiher AM, Scheffer MP, Frangakis AS, Yin X, Mayr M, et al. Atheroprotective communication between endothelial cells and smooth muscle cells through miRNAs. Nature Cell Biology $2012 \mathbf{1 4}$ 249-256. (https://doi.org/10.1038/ncb2441)

31 Krizhanovsky V, Yon M, Dickins RA, Hearn S, Simon J, Miething C, Yee H, Zender L \& Lowe SW. Senescence of activated stellate cells limits liver fibrosis. Cell $2008 \mathbf{1 3 4}$ 657-667. (https://doi. org/10.1016/j.cell.2008.06.049)

32 Montecino-Rodriguez E, Berent-Maoz B \& Dorshkind K. Causes, consequences, and reversal of immune system aging. Journal of
Clinical Investigation 2013123 958-965. (https://doi.org/10.1172/ JCI64096)

33 Ovadya Y, Landsberger T, Leins H, Vadai E, Gal H, Biran A, Yosef R, Sagiv A, Agrawal A, Shapira A, et al. Impaired immune surveillance accelerates accumulation of senescent cells and aging. Nature Communications 20189 5435. (https://doi.org/10.1038/s41467-01807825-3)

34 Baker DJ, Wijshake T, Tchkonia T, LeBrasseur NK, Childs BG, van de Sluis B, Kirkland JL \& van Deursen JM. Clearance of p16Ink4apositive senescent cells delays ageing-associated disorders. Nature 2011479 232-236. (https://doi.org/10.1038/nature10600)

35 Zhu Y, Tchkonia T, Pirtskhalava T, Gower AC, Ding H, Giorgadze N, Palmer AK, Ikeno Y, Hubbard GB, Lenburg M, et al. The Achilles' heel of senescent cells: from transcriptome to senolytic drugs. Aging Cell 201514 644-658. (https://doi.org/10.1111/acel.12344)

36 Xu M, Pirtskhalava T, Farr JN, Weigand BM, Palmer AK, Weivoda MM, Inman CL, Ogrodnik MB, Hachfeld CM, Fraser DG, et al. Senolytics improve physical function and increase lifespan in old age. Nature Medicine 201824 1246-1256. (https://doi. org/10.1038/s41591-018-0092-9)

37 Childs BG, Baker DJ, Wijshake T, Conover CA, Campisi J \& van Deursen JM. Senescent intimal foam cells are deleterious at all stages of atherosclerosis. Science 2016354 472-477. (https://doi. org/10.1126/science.aaf6659)

38 Gardner SE, Humphry M, Bennett MR \& Clarke MC. Senescent vascular smooth muscle cells drive inflammation through an interleukin-1alpha-dependent senescence-associated secretory phenotype. Arteriosclerosis, Thrombosis, and Vascular Biology 201535 1963-1974. (https://doi.org/10.1161/ ATVBAHA.115.305896)

39 Roos CM, Zhang B, Palmer AK, Ogrodnik MB, Pirtskhalava T, Thalji NM, Hagler M, Jurk D, Smith LA, Casaclang-Verzosa G, et al. Chronic senolytic treatment alleviates established vasomotor dysfunction in aged or atherosclerotic mice. Aging Cell $2016 \mathbf{1 5}$ 973-977. (https://doi.org/10.1111/acel.12458)

40 Justice JN, Nambiar AM, Tchkonia T, LeBrasseur NK, Pascual R, Hashmi SK, Prata L, Masternak MM, Kritchevsky SB, Musi N, et al. Senolytics in idiopathic pulmonary fibrosis: results from a firstin-human, open-label, pilot study. eBiomedicine 201940 554-563. (https://doi.org/10.1016/j.ebiom.2018.12.052)

41 Hekmatimoghaddam S, Dehghani Firoozabadi A, Zare-Khormizi MR \& Pourrajab F. Sirt1 and Parp1 as epigenome safeguards and microRNAs as SASP-associated signals, in cellular senescence and aging. Ageing Research Reviews 201740 120-141. (https://doi. org/10.1016/j.arr.2017.10.001)

42 Mellis D \& Caporali A. MicroRNA-based therapeutics in cardiovascular disease: screening and delivery to the target. Biochemical Society Transactions 201846 11-21. (https://doi. org/10.1042/BST20170037)

Received in final form 25 July 2019

Accepted 12 August 2019

Accepted Preprint published online 12 August 2019 (c) 2019 The authors Published by Bioscientifica Ltd

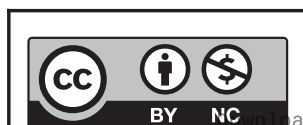

This work is licensed under a Creative Commons Attribution-NonCommercial 4.0 International License.

ded from Bioscientifica.com at 04/26/2023 06:43:25AM 